\title{
Thymic Microenvironment and Lymphoid Responses to Sublethal Irradiation
}

\author{
ELISE S. RANDLE-BARRETT*' ${ }^{\dagger}$ and RICHARD L. BOYD \\ ${ }^{\dagger}$ Department of Pathology and Immunology, Monash Medical School, Commercial Road, Prahran, 3181, Vic, Australia
}

\begin{abstract}
Sublethal irradiation of the murine thymus has been a useful tool for depleting the thymus of dividing immature thymocyte subsets, to sequence thymocyte differentiation events occurring from radiation-resistant precursors. This massive reduction in thymocytes also represents a model in which the bidirectional interplay between the thymic stromal cells and lymphocytes can be investigated. The purpose of this study was thus twofold: to precisely map the initiation of thymopoiesis as a prelude to assessing the effects of injected $\mathrm{mAb}$ to novel thymic antigens; and to use a panel of mAbs to determine the alterations in the thymic stroma during the T-cell depletion and reconstitution phases. The striking finding from this study was that following T-cell depletion, there was a marked upregulation of specific stromal antigens, which retracted with the reappearance of $T$ cells. Thus, following sublethal irradiation, there are modifications in the thymic microenvironment that may be necessary to support renewed thymopoiesis and the complete restoration of the thymus involved the synchronous development of both the stromal and lymphocytic components.
\end{abstract}

KEYWORDS: T-cell, thymus, irradiation, thymocyte.

\section{INTRODUCTION}

The thymic microenvironment consists of specialized cells that are both epithelial and nonepithelial in nature. Together these cellular elements are organized into well-defined cortical and medullary regions, throughout which developing thymocytes reside (Boyd et al., 1993). As $\mathrm{T}$ cells mature within the thymus, they migrate from the cortex to the medulla and undergo phenotypic changes, including the acquisition of TcR, cytokine receptors, and the modulation of differentiation antigens such as CD4 and CD8 (Boyd and Hugo, 1991). The contribution of the thymic microenvironment toward this complex process, and that which thymocytes themselves impart on the thymic microenvironment, is gradually becoming defined. Thymic stromal cells such as TNC, M $\phi$, and DC form complexes with developing thymocytes (Andrews and Boyd, 1985; Kyewski, 1986; van Ewijk, 1988; Shortman and Vremec, 1991; Gao et al., 1993) and stromal cell lines instruct some, but not all, specific stages of

\footnotetext{
* Corresponding author.
}

thymocyte development (Palacios et al., 1989; Nishimura et al., 1990; Tatsumi et al., 1990; Nagamine et al., 1991; Hugo et al., 1992; Watanabe et al., 1992; Anderson et al., 1993). Accordingly, damage to the microenvironment itself via drug treatment or ionizing irradiation impairs thymocyte differentiation (Adkins et al., 1988; Kanariou et al., 1989).

That the constitution and organization of the thymic microenvironment are in turn dependent on T-cell development has been well illustrated in a number of experimental systems. In SCID mice and in mice deficient in RAG- 1 or p56 $6^{\text {lck }}$, the medulla fails to develop due to the absence of mature $\mathrm{TcR}^{+}$ thymocytes (Shores et al., 1991; Molina et al., 1992; Suhr et al., 1992; Ritter and Boyd, 1993; van Ewijk et al., 1994). Similarly, in TcR knockout mice, where thymocyte development is blocked beyond $\mathrm{CD} 4^{+} \mathrm{CD}^{+}$cells, the medulla is greatly reduced in size (Philpott et al., 1992; Palmer et al., 1993; Mombaerts et al., manuscript in preparation). This effect has also been demonstrated in mice that have been injected with anti-CD3 mAb (Kyewski, 1991). Furthermore, a thymocyte-stromal cell signaling pathway in which medullary epithelial cells are activated via the phosphorylation of a $90-\mathrm{kD}$ 
medullary epithelial-cell glycoprotein upon contact with $\mathrm{CD} 4^{+} \mathrm{CD} 8^{+}$thymocytes has been identified (Couture et al., 1992). Thus, it is evident that a bidirectional relationship exists between thymocytes and stromal cells (reviewed by Ritter and Boyd, 1993).

In the present study, we have mapped thymocyte reconstitution post-irradiation (PIrr) to ultimately devize a model for examining the in vivo effects specific $\mathrm{mAbs}$ have on thymopoiesis. Using a panel of mAb-recognizing mouse thymic stromal (MTS) antigens derived in this laboratory (Godfrey et al., 1990; Tucek et al., 1992), we also observed the effects of irradiation and the associated loss of $\mathrm{T}$ cells on the thymic microenvironment. In agreement with others (Huiskamp et al., 1983; Huiskamp and van Ewijk, 1985; Adkins et al., 1988), the initial loss of lymphocytes following irradiation resulted in the collapse of the stromal architecture, in particular, that of the cortex. Most importantly, however, it was clearly illustrated that the thymic was "dynamic" immediately following irradiation, with marked upregulation in the expression of specific cortical and medullary stromal antigens. These selective changes in the thymic stroma may have been as a direct result of the irradiation itself, revealed as a consequence of the rapid depletion of thymocytes or a prerequisite for the initiation of thymopoiesis following irradiation.

\section{RESULTS}

\section{Effect of Irradiation on Thymocyte Subpopulations}

Total Thymocyte Cell Number. Total cell yields dramatically decreased immediately following sublethal irradiation (Fig. 1) from their normal adult value (day 0) of $6.0 \pm 1.4 \times 10^{7}$ to the nadir of $4.2 \pm$ $1.2 \times 10^{5}$, by day 5 . Between days 6 and 7 , however, there was extensive thymocyte proliferation as indicated by the tenfold increase in total cell number to $4.4 \pm 0.31 \times 10^{6}$, with an additional tenfold increase in number by day 12 to $3.3 \pm 0.2 \times 10^{7}$.

$C D 3, C D 4$, and $C D 8$ Expression. To assess thymocyte subpopulations and their subsequent reconstitution, thymocytes on days 1-14, 21, and 28 PIrr were stained simultaneously for CD3, CD4, and CD8 antigen expression. By day 1 , the thymus is virtually devoid of $\mathrm{CD}^{+}{ }^{+} \mathrm{CD} 8{ }^{+}$double-positive (DP) thymo-

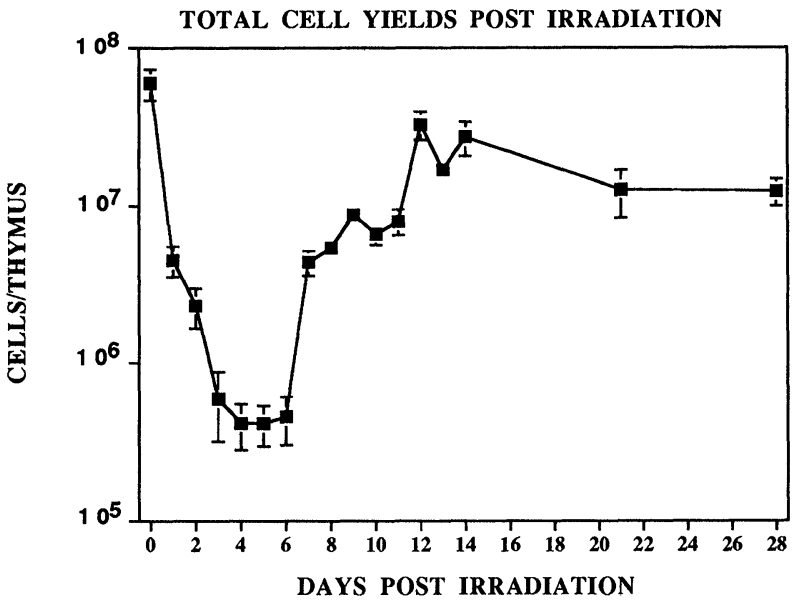

FIGURE 1. Total thymocyte cell yields of normal adult CBA/ $\mathrm{CaH}$ (day 0 ) mice and sublethally irradiated mice, 1-28 days postirradiation. Results represent the mean \pm standard deviation of four independent experiments, except for days 8, 9, and 13, which are represented as the mean of two experiments.

cytes (Fig. 2), the small remnant population being mainly of the $\mathrm{CD} 4^{+} \mathrm{CD} 8^{+} \mathrm{CD} 3^{\text {hi }}$ subset (Fig. 3). The resistance of mature populations to the irradiation was further reflected in the mature $\left(\mathrm{CD}^{+}\right) \mathrm{CD} 4$ and CD8 single-positive populations. Although these cells markedly increased in proportion within the first 4 days (Figs. 2 and 3), they progressively decreased in number (from $4.3 \pm 1.0 \times 10^{6}$ to $7.5 \pm 0.7 \times 10^{4}$ and $1.2 \pm 0.4 \times 10^{6}$ to $1.8 \pm 3.0 \times 10^{4}$, respectively) until day 10 , presumably due to emigration (K. Kelly, personal communication). Similarly, $\mathrm{CD}^{+}{ }^{+} \mathrm{CD} 4^{-} \mathrm{CD} 8^{-}$thymocytes were unaffected proportionally (Fig. 3) but decreased in number from $3.0 \pm 0.8 \times 10^{5}$ to $1.0 \pm 1.0 \times 10^{4}$ by day 5 .

The immature $\mathrm{CD}^{-} \mathrm{CD} 4^{-} \mathrm{CD} 8^{-}$triple-negative (TN) thymocytes were relatively increased initially, but by day 3 had decreased in both proportion (Fig. 3 ) and cell number (from $9.0 \pm 3.0 \times 10^{5}$ to $1.2 \pm 1.0 \times 10^{4}$ ), those remaining being the radiationresistant cells that subsequently give rise to thymic reconstitution (Sharp and Thomas, 1977; Hiesch and Revesz, 1979). Immature CD4 and CD8 singlepositive populations were also reduced tenfold in number by day 4 (from $9.5 \pm 2.0 \times 10^{5}$ to $1.0 \pm 0.5 \times 10^{4}$ and $4.0 \pm 2.0 \times 10^{5}$ to $0.3 \pm 0.1 \times 10$, respectively) although unaffected in proportion within the first 3 to 4 days (Fig. 3).

Thymic reconstitution began around day 4 with sequential, progressive increases in $\mathrm{CD}^{-} \mathrm{CD}^{-}$ CD8 ${ }^{-}$cells (Figs. 2 and 3), some of which progressed to the immature single-positive and subsequently 


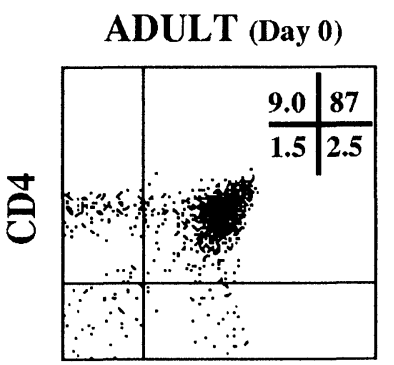

CD8
TOTAL CD3

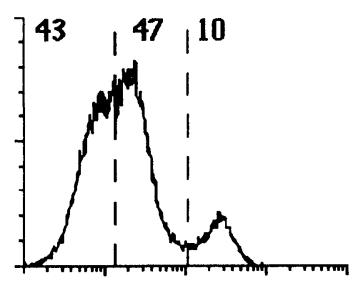

DAY 1
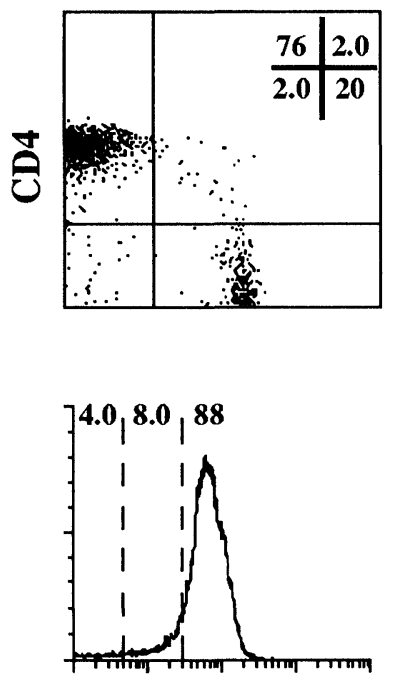

DAY 6
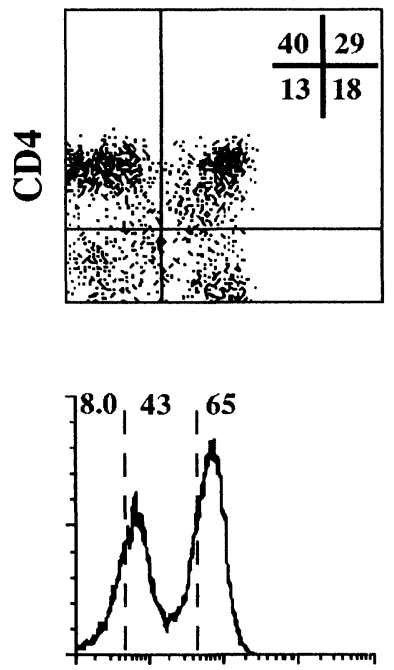

DAY 3

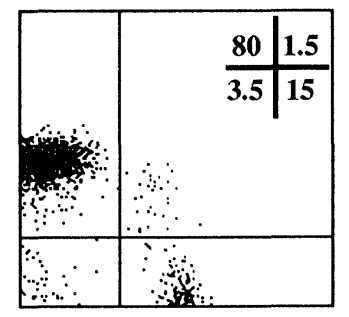

\section{CD8}
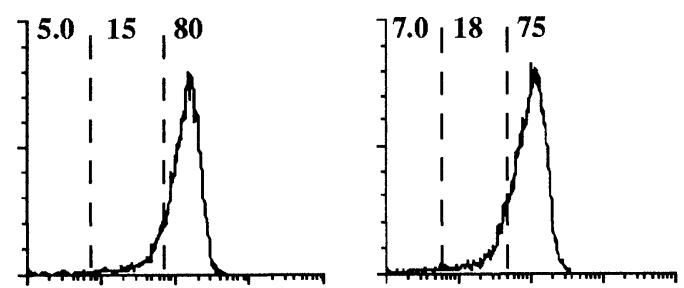

DAY 7

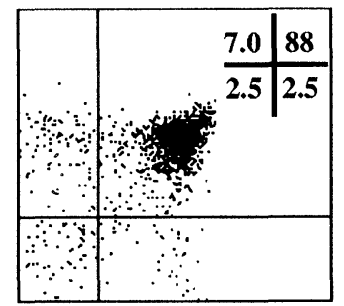

DAY 12

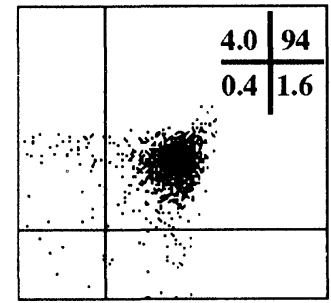

CD8

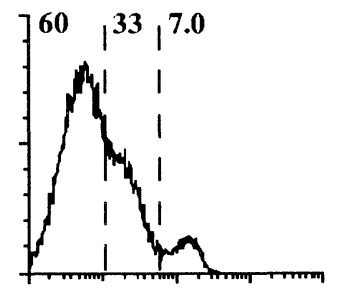

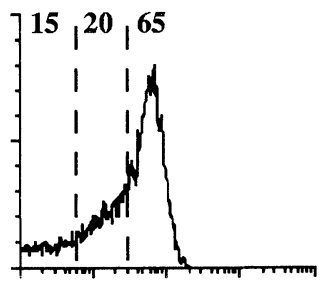

DAY 5

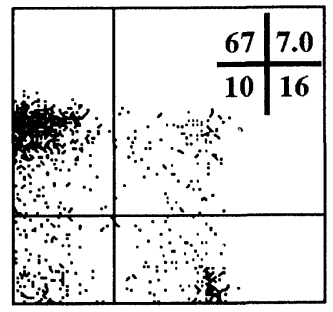

DAY 28
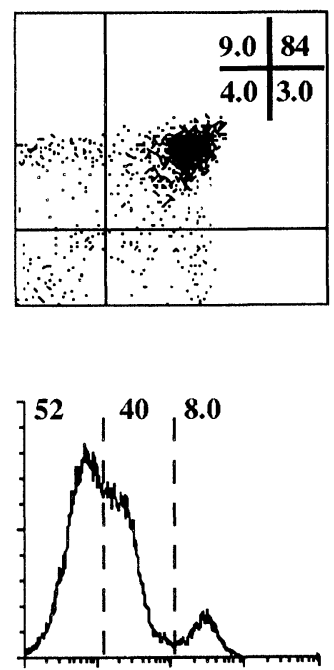

FIGURE 2. Three-color FCM analysis of CD3, CD4, and CD8 antigen expression on thymocytes from nonirradiated adult CBA/CaH mice and sublethally irradiated mice 1-28 days following irradiation. Definition of CD4/CD8 subsets and total CD3 expression are based on cursor settings defined from nonirradiated adult CBA thymocytes. The results were obtained by analysis of $3.0 \times 10^{4}$ cells and represent four to five independent experiments. 

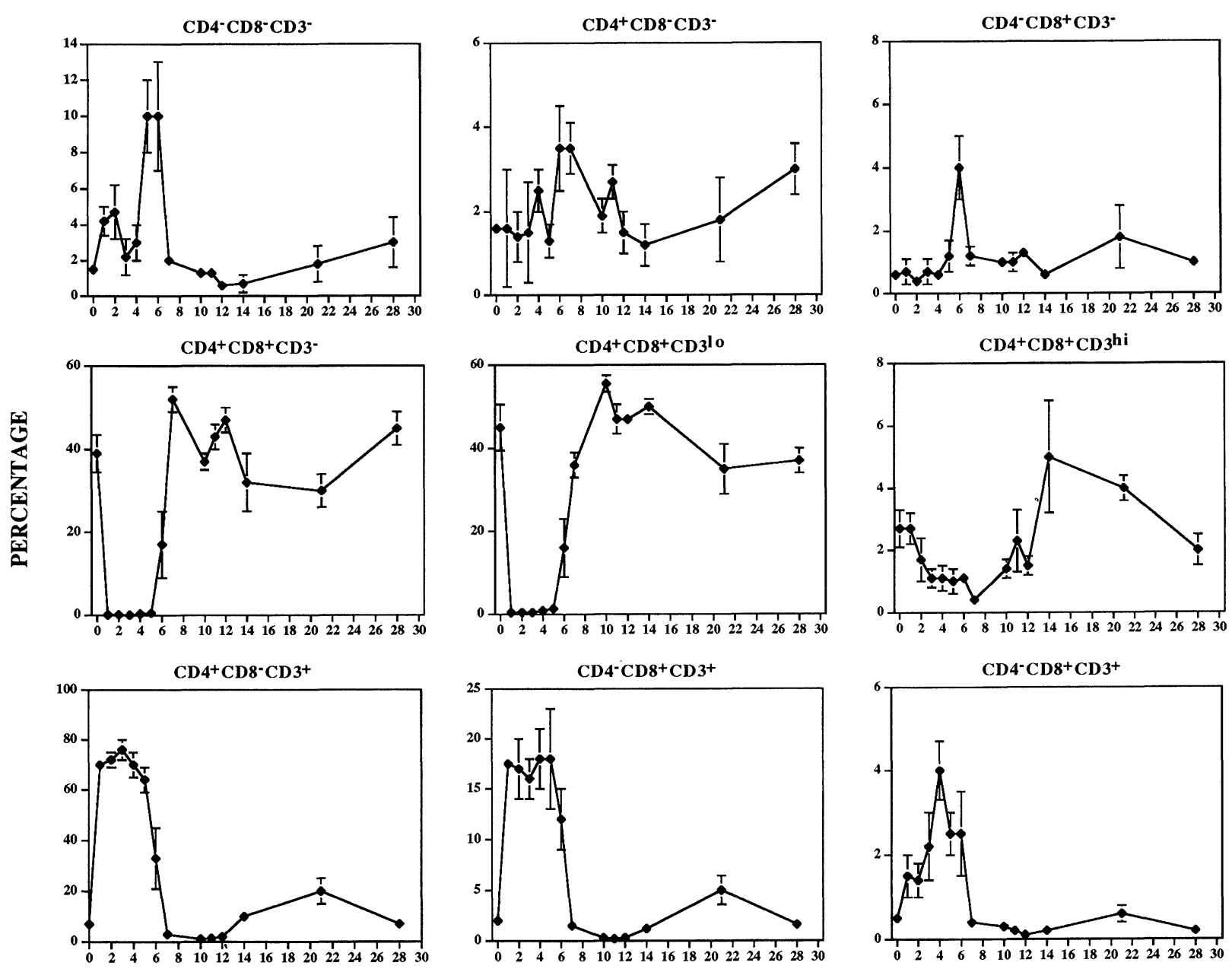

FIGURE 3. Mean percentage values \pm standard deviations for CD3/CD4/CD8-defined thymocyte populations 1-28 days following sublethal irradiation. Day 0 represents adult CBA nonirradiated thymocytes. Results were obtained by FCM analysis of $3.0 \times 10^{4}$ cells and represent three to five independent experiments.

$\mathrm{CD} 4^{+} \mathrm{CD} 8^{+}$cells. Thus, between days 5-7 following irradiation, all immature thymocyte populations markedly expanded. By day 7 , the thymocyte profile with respect to $\mathrm{CD} 3, \mathrm{CD} 4$, and $\mathrm{CD} 8$ expression approximated that of the adult thymus (Fig. 2), although it is not clear whether the mature singlepositive cells were remnant radiation-resistant cells that had not yet migrated or were derived from de novo production of differentiating precursors. From day 7, all thymocyte populations increased in cell number, and by day 21, normal adult values were virtually attained (data not shown).

MTS 32, 33, 35 and 37. MTS 32, 33, 35, and 37 identify antigens with the unusual property of being expressed on both thymocytes and thymic stromal cells, thereby providing an additional phenotypic profile of thymocytes distinct from that defined by CD3, CD4, and CD8 expression (Godfrey et al., 1990; Tucek et al., 1992). On thymocytes, MTS 32 stains all $\mathrm{T}$ cells, except a subset of $\mathrm{CD} 3{ }^{\text {hi }} \mathrm{CD} 4^{+}$ CD8 ${ }^{-}$cells, which exhibit a Th0/Th2-type cytokine profile (Vacari et al., 1994); MTS 33 and 37, which detect ThB and HSA, respectively, stain immature thymocytes and mature thymocytes, but are negative on peripheral T cells; MTS 35, detects the antigen TSA-1/Sca-2, which is restricted to immature thymocytes and has an inverse expression to CD3 (Godfrey et al., 1992). Figure 4 shows the effect of sublethal irradiation on the four thymocyte determinants. MTS 32 progressively decreased from $96 \%$ to $60 \%$ by day 4 PIrr, and then gradually 
MTS 32

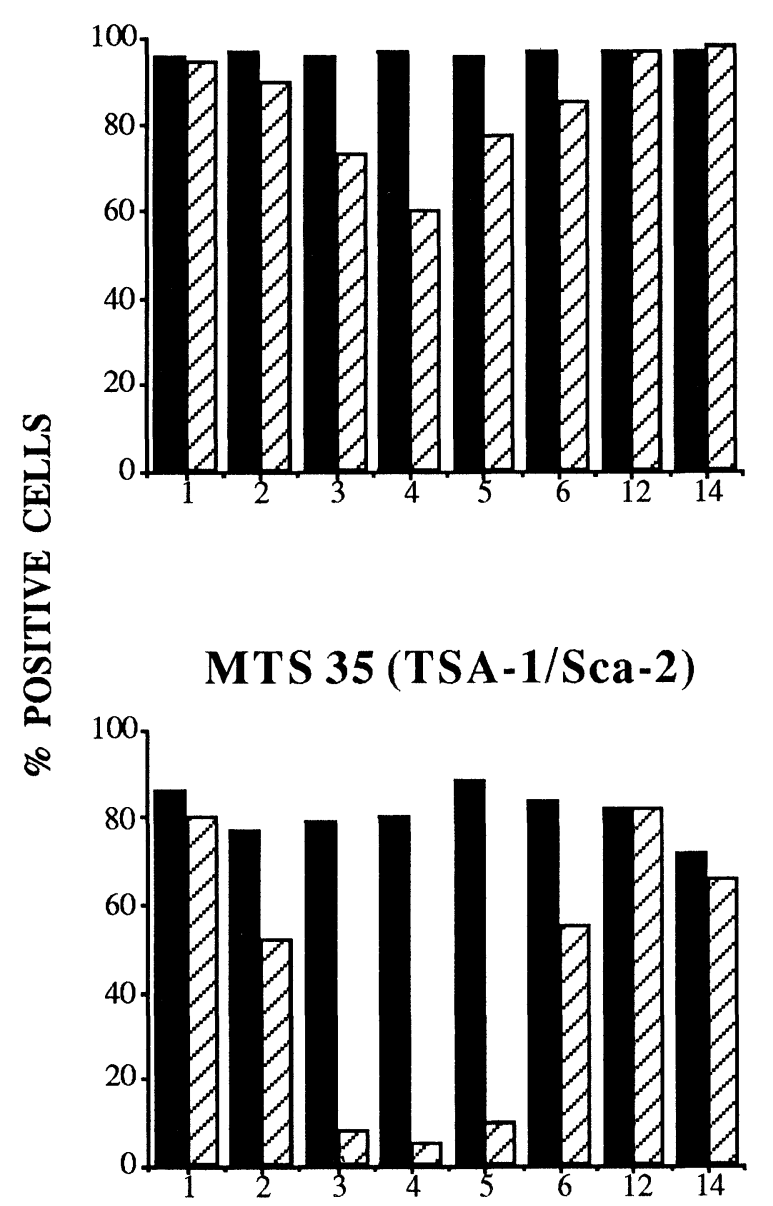

MTS 33 (ThB)
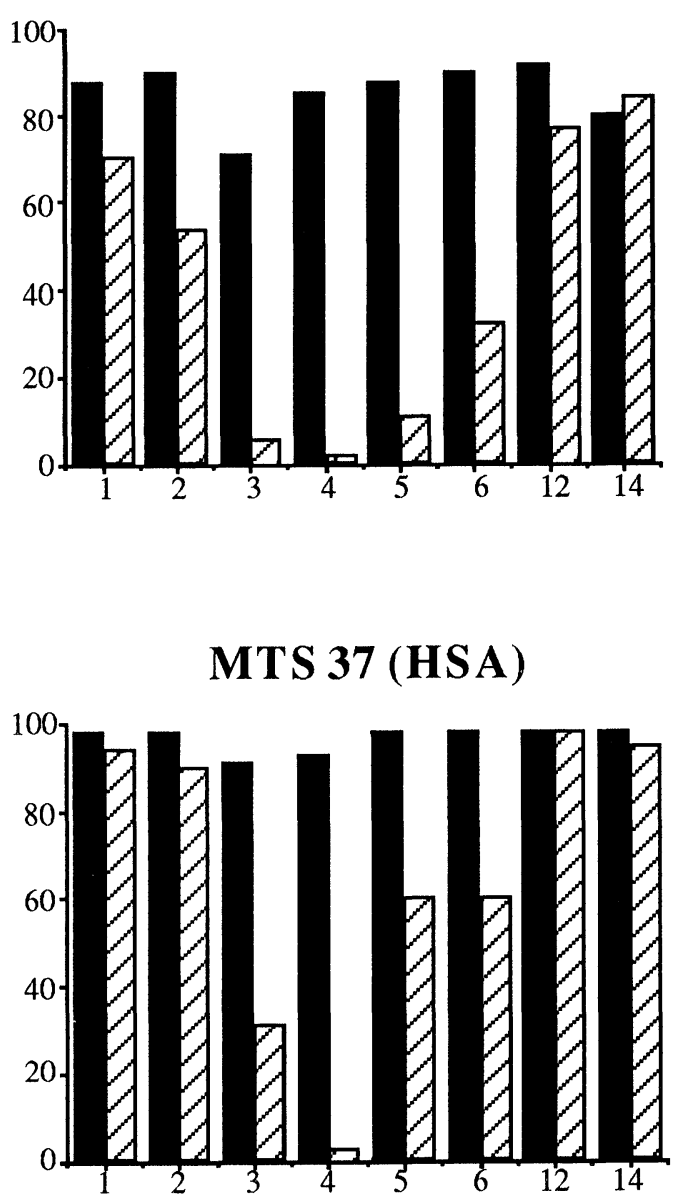

DAYS POST IRRADIATION

FIGURE 4. Percentage of thymocyte subpopulations defined by MTS mAb for sham irradiated (filled-in bars) and sublethally irradiated (lined bars) mice days 1-14 post-irradiation. Results represent the mean of two concordant experiments.

increased to approximately the adult values by day 12. In accordance with the dramatic loss of immature thymocytes, PIrr, ThB, TSA-1/Sca-2, and HSA expression were markedly reduced from approximately $90 \%$ to $2-5 \%$ by day 4 , despite the fact that HSA and ThB are expressed on mature $\mathrm{CD}^{+}$cells, albeit at low levels, which are virtually the only cells remaining after irradiation.

\section{Effect of Irradiation on the Thymic Microenvironment}

The effects of sublethal irradiation on the thymic microenvironment were examined using an extensive panel of mAbs reactive with epithelial and nonepithelial stromal cells and the vasculature, the normal adult thymus reactivities have been described elsewhere (Godfrey et al., 1990). The data are summarized in Tables 1 to 4 .

Epithelial Cells. Following irradiation, the loss of rapidly dividing thymocytes and decrease in thymus size were associated with a collapse of the thymic stromal network, particularly that of the cortex. This was well illustrated by anti-CD4 and anticytokeratin labeling of the thymic epithelium (Fig. 5). Similarly, MTS 44 is pan-cortical epithelium, but also weakly stains infrequent, isolated medullary epithelial cells in the normal adult thymus. By 3 days PIrr, MTS $44^{+}$epithelial cells formed a compact 
TABLE 1.1

Epithelium

\begin{tabular}{|c|c|c|c|c|c|c|c|c|c|}
\hline \multirow{2}{*}{$\begin{array}{l}\text { MTS } \\
\mathrm{mAb}\end{array}$} & \multirow{2}{*}{$\begin{array}{l}\text { Reference } \\
\text { Thymus }\end{array}$} & \multicolumn{8}{|c|}{ POST-IRRADIATION } \\
\hline & & $12 \mathrm{~h}$ & Day 1 & Day 2 & Day 3 & Day 4 & Day 5 & Day 6 & Day 12 \\
\hline 44 & $\begin{array}{l}\text { C: Ep } \\
\text { M: Ep Sp }\end{array}$ & $\mathrm{NC}^{*}$ & $\mathrm{NC}^{*}$ & $\mathrm{NC}^{*}$ & C: Outer Ep & C: Outer Ep & C: Outer Ep & $\mathrm{NC}^{*}$ & $\mathrm{NC}$ \\
\hline 10 & M \& Sc: Ep & $\mathrm{NC}^{*}$ & C: Ep & C: Ep & $C: E p$ & C: Ep & C: Ep & $\mathrm{NC}^{*}$ & $\mathrm{NC}$ \\
\hline $\begin{array}{l}6 \\
(\mathrm{MHC}-\mathrm{II})\end{array}$ & $\begin{array}{l}\text { Pan Ep } \\
\text { M: KNC \& Thy Sp } \\
\text { C: Thy Sp }\end{array}$ & $\mathrm{NC}^{*}$ & $\begin{array}{l}\text { M: Ep } \\
\text { C: confluent } \\
\text { M: NC }\end{array}$ & $\begin{array}{l}\text { M: Ep } \\
\text { C: confluent } \\
\text { M: NC }\end{array}$ & $\begin{array}{l}\text { M: Ep } \\
\text { C: confluent } \\
M: N C\end{array}$ & $\begin{array}{l}\text { M: Ep } \\
\text { C: confluent } \\
\text { M: NC }\end{array}$ & $\begin{array}{l}\text { M: Ep } \\
\text { C: confluent } \\
\text { M: NC }\end{array}$ & $\mathrm{NC}^{*}$ & $\mathrm{NC}$ \\
\hline 9 & $\begin{array}{l}\text { C: Isol Ep \& Thy Sp } \\
\text { M: Ep \& Thy Sp }\end{array}$ & $\mathrm{NC}^{*}$ & $\begin{array}{l}\text { C: confluent } \\
\text { M: EP } \uparrow\end{array}$ & $\begin{array}{l}\text { C: confluent } \\
\text { M: EP } \uparrow\end{array}$ & $\begin{array}{l}\text { C: confluent } \\
\mathrm{M}: \mathrm{EP} \uparrow\end{array}$ & $\begin{array}{l}\text { C: confluent } \\
\text { M: EP } \uparrow\end{array}$ & $\begin{array}{l}\text { C: patchy } \\
\text { M: EP } \uparrow\end{array}$ & $\mathrm{NC}^{*}$ & NC \\
\hline
\end{tabular}

Abbreviations: BV: blood vessels; C: cortex; ECM: extracellular matrix: Ep: epithelium; Isol: isolated; IVC: intravascular cells; KNC: keratin-negative cells; M: medulla; NC: no change, $\mathrm{mAb}$ reactivity reflects that of reference thymus; $\mathrm{NC}^{*}$ : no change, mAb reactivity reflects that of the reference thymus but stromal architecture is collapsed; PVS: perivascular space; Sc: subcapsule; Sp: subpopulation; Thy: thymocytes.

TABLE 1.2

Vascular/Connective Tissue Associated Elements

\begin{tabular}{|c|c|c|c|c|c|c|c|c|c|}
\hline \multirow{2}{*}{$\begin{array}{l}\text { MTS } \\
\text { mAb }\end{array}$} & \multirow{2}{*}{$\begin{array}{l}\text { Reference } \\
\text { Thymus }\end{array}$} & \multicolumn{8}{|c|}{ POST-IRRADIATION } \\
\hline & & $12 \mathrm{~h}$ & Day 1 & Day 2 & Day 3 & Day 4 & Day 5 & Day 6 & Day 12 \\
\hline 12 & Capillaries & $\mathrm{NC}^{*}$ & $\uparrow$ & $\uparrow$ & $\uparrow$ & $\uparrow$ & $\uparrow$ & $\uparrow$ & NC \\
\hline 15 & $\begin{array}{l}\text { Granular staining } \\
\text { around BV, in PVS \& Sc space }\end{array}$ & $\mathrm{NC}^{*}$ & $\uparrow$ & $\uparrow$ & $\uparrow$ & $\uparrow$ & $\uparrow$ & $\uparrow$ & $\mathrm{NC}$ \\
\hline 16 & $\begin{array}{l}\text { Basement membrane } \\
\text { associated ECM }\end{array}$ & $\mathrm{NC}^{*}$ & $\uparrow$ & $\uparrow$ & $\uparrow$ & $\uparrow$ & $\uparrow$ & $\uparrow$ & $\mathrm{NC}$ \\
\hline
\end{tabular}

TABLE 1.3

Isolated Stromal Elements

\begin{tabular}{|c|c|c|c|c|c|c|c|c|c|}
\hline \multirow{2}{*}{$\begin{array}{l}\text { MTS } \\
\mathrm{mAb} \\
\end{array}$} & \multirow{2}{*}{$\begin{array}{l}\text { Reference } \\
\text { Thymus }\end{array}$} & \multicolumn{8}{|c|}{ POST-IRRADIATION } \\
\hline & & $12 \mathrm{~h}$ & Day 1 & Day 2 & Day 3 & Day 4 & Day 5 & Day 6 & Day 12 \\
\hline $17 \mathrm{~h}$ & M \& Sc: Isol KNC & $\mathrm{NC}$ & $\mathrm{C}: \mathrm{KNC} \uparrow$ & $\mathrm{C}: \mathrm{KNC} \uparrow$ & $\begin{array}{l}\text { M: } \operatorname{Ep}(\mathrm{HC}) \\
\mathrm{KNC} \uparrow\end{array}$ & $\begin{array}{l}\text { M: Ep(HC); } \\
\text { KNC } \uparrow\end{array}$ & $\begin{array}{l}\text { M: Ep(HC); } \\
\text { KNC } \uparrow\end{array}$ & $\mathrm{NC}^{*}$ & $\mathrm{NC}$ \\
\hline 29 & M: Isol Ep cells & $\mathrm{NC}$ & $\mathrm{NC}^{*}$ & $\mathrm{NC}^{*}$ & $\mathrm{M}: \mathrm{KNC} \uparrow$ & $\mathrm{M}: \mathrm{KNC} \uparrow$ & $\mathrm{M}: \mathrm{KNC} \uparrow$ & $\mathrm{NC}^{*}$ & $\mathrm{NC}$ \\
\hline
\end{tabular}

TABLE 1.4

Thymocyte-Stromal-Cell Shared Antigens

\begin{tabular}{|c|c|c|c|c|c|c|c|c|c|}
\hline \multirow{2}{*}{$\begin{array}{l}\text { MTS } \\
\text { mAb }\end{array}$} & \multirow{2}{*}{$\begin{array}{l}\text { Reference } \\
\text { Thymus }\end{array}$} & \multicolumn{8}{|c|}{ POST-IRRADIATION } \\
\hline & & $12 \mathrm{~h}$ & Day 1 & Day 2 & Day 3 & Day 4 & Day 5 & Day 6 & Day 12 \\
\hline 32 & C: Thy \& Ep & $\mathrm{NC}^{*}$ & $\begin{array}{c}\text { C: Isol Ep; } \\
\downarrow \downarrow \text { Thy }\end{array}$ & $\begin{array}{c}\text { C: Isol Ep; } \\
\downarrow \text { Thy }\end{array}$ & $\begin{array}{l}\text { C: Isol Ep; } \\
\downarrow \downarrow \text { Thy }\end{array}$ & $\begin{array}{l}\text { C: Isol Ep; } \\
\quad \downarrow \text { Thy }\end{array}$ & $\begin{array}{l}\text { C: Isol Ep; } \\
\downarrow \text { Thy }\end{array}$ & C: Isol Ep; & $\mathrm{NC}$ \\
\hline $\begin{array}{l}33 \\
\text { (ThB) }\end{array}$ & $\begin{array}{l}\text { C: Thy } \\
\text { M: Ep clusters }\end{array}$ & $\mathrm{NC}^{*}$ & $\begin{array}{l}\text { C: Isol Ep } \\
\text { M: Ep } \uparrow\end{array}$ & $\begin{array}{l}\text { C: Isol Ep } \\
\text { M: Ep } \uparrow\end{array}$ & $\begin{array}{l}\text { C: Isol Ep } \\
\text { M: Ep } \uparrow\end{array}$ & $\begin{array}{l}\text { C: Isol Ep } \\
\text { M: Ep } \uparrow\end{array}$ & $\begin{array}{l}\text { C: Isol Ep } \\
\text { M: Ep } \uparrow\end{array}$ & $\begin{array}{l}\text { NC } \\
\text { M: Ep } \uparrow\end{array}$ & \\
\hline $\begin{array}{l}35 \\
\text { (TSA-1/ } \\
\text { Sca-2) }\end{array}$ & $\begin{array}{l}\text { C: Thy } \\
\text { M: Isol Ep cells }\end{array}$ & $\mathrm{NC}^{*}$ & C: Isol Ep & C: Isol Ep & $\begin{array}{l}\text { M: KNC; } \\
\text { Isol Ep } \uparrow\end{array}$ & $\begin{array}{l}\text { M: KNC; } \\
\text { Isol Ep } \uparrow\end{array}$ & $\begin{array}{l}\text { M: KNC; } \\
\text { Isol Ep } \uparrow\end{array}$ & $\mathrm{NC}^{*}$ & NC \\
\hline $\begin{array}{l}37 \\
\text { (HSA) }\end{array}$ & $\begin{array}{l}\text { C, M, \& PVS: Isol } \\
\text { Ep \& KNC, IVC } \\
\text { \& Thy }\end{array}$ & $\mathrm{NC}^{*}$ & $\mathrm{C}: \mathrm{KNC} \uparrow$ & $\mathrm{C}: \mathrm{KNC} \uparrow$ & $\begin{array}{l}\text { M: KNC } \uparrow \\
\mathrm{C}: \mathrm{Ep} \uparrow\end{array}$ & $\begin{array}{l}\text { M: KNC } \uparrow \\
\mathrm{C}: \mathrm{Ep} \uparrow\end{array}$ & $\begin{array}{l}\mathrm{M}: \mathrm{KNC} \uparrow \\
\mathrm{C}: \mathrm{Ep} \uparrow\end{array}$ & $\mathrm{NC}^{*}$ & NC \\
\hline
\end{tabular}

Abbreviations: See footnote for Table 1. 

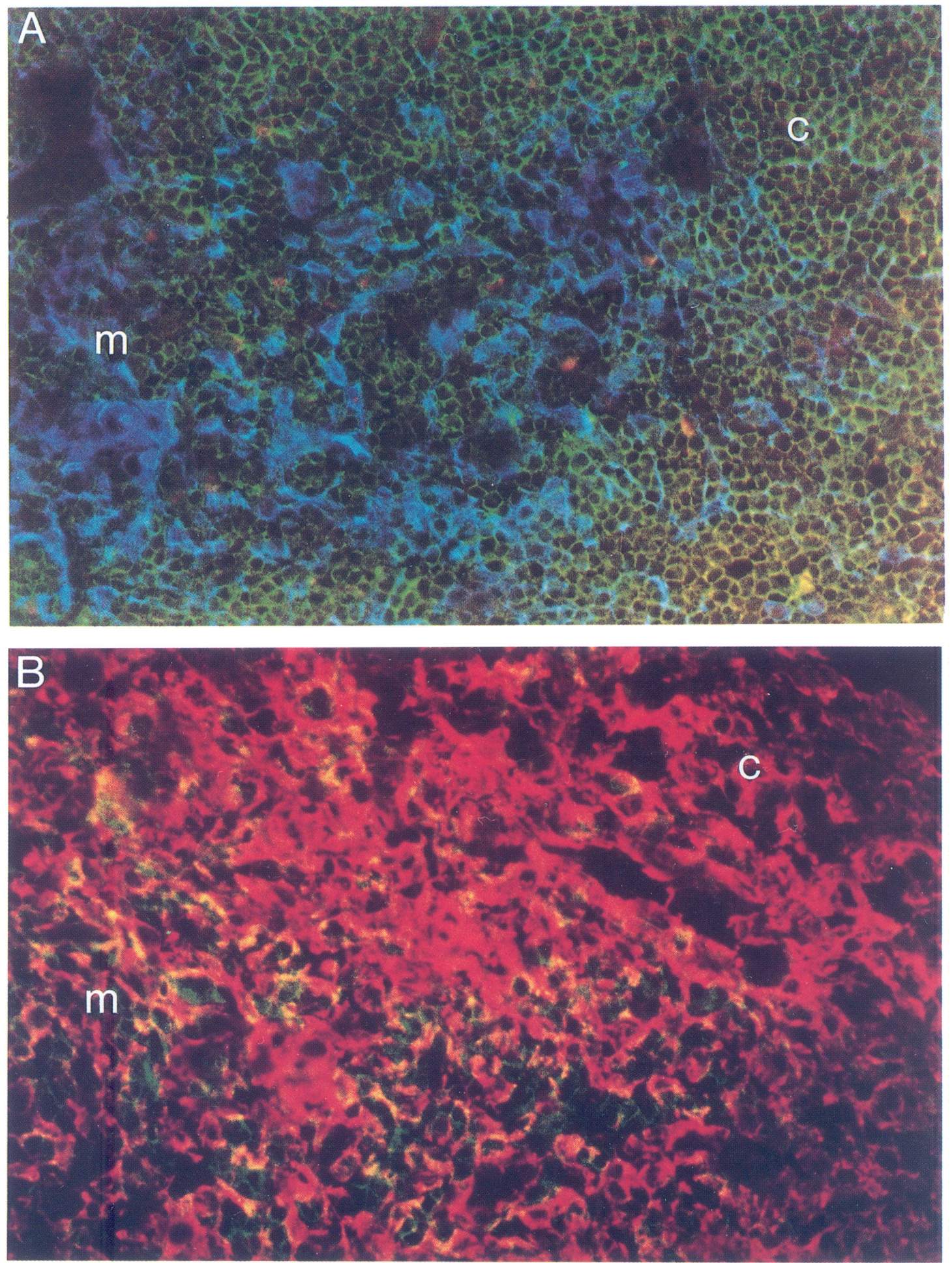

FIGURE 5. (A) Normal adult thymus stained with anti-keratin (blue), anti-CD4 (green), and anti-CD8 (red). Three-color immunofluorescence clearly shows a distinct medulla $(\mathrm{m})$ and cortex $(\mathrm{c})$ as defined by anti-keratin in which thymocytes as defined by CD4 and CD8 (orange) reside. Cells positive for both CD4 and CD8 are denoted by yellow staining $(\times 640)$. (B) Two-color immunofluorescence $24 \mathrm{~h}$ after sublethal irradiation shows that irradiation resulted in an elimination of thymocytes, as defined by CD4 (green), and collapse of the thymic epithelial network, particularly that of the cortex, as defined by anti-keratin (red) $(\times 640)$. See Colour Plate I. 

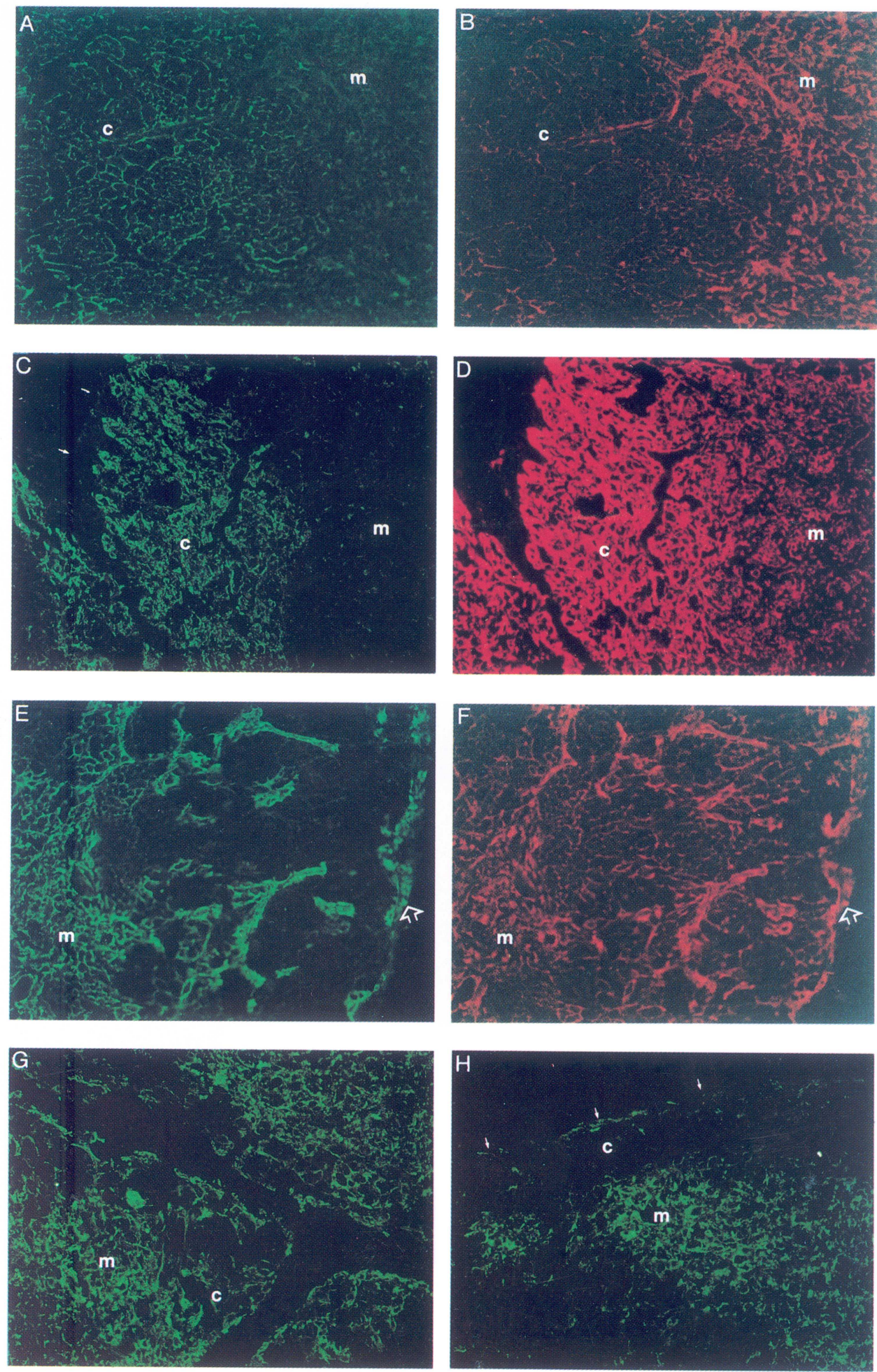

FIGURE 6. Effect of irradiation on cortical and medullary epithelium. MTS mAb (green) double-labeled with anti-keratin (red). In the normal adult thymus, MTS 44 stains cortical (c) and isolated medullary (m) epithelium (A; $\times 110)$; anti-keratin (B). Post-irradiation, particularly between $24-48 \mathrm{~h}$, MTS $44^{+}$cortical (c) epithelial cells increased in density (C; $\left.\times 110\right)$; double-labeled with anti-keratin (D). MTS 10, a marker of subcapsular (arrow) and medullary epithelium in the normal adult thymus $(\mathrm{E}$; $\times 110$ ); double-labeled with anti-keratin $(F)$, showed cortical (c) epithelial expression post-irradiation (G; $24 \mathrm{~h}$ PIrr; $\times 110$ ). By day 6 PIrr, MTS 10 again showed the normal subcapsular (arrow) and medullary $(\mathrm{m})$ distribution $(\mathrm{H} ; \times 220)$, similar to the nonirradiated adult thymus. See Colour Plate II. 
zone around the medulla, corresponding to the collapsed cortex (Figs. 6A-6D). There was no apparent numerical loss of cortical epithelial cells, the MTS 44 distribution normalizing concomitant with the reappearance of the thymocytes beginning from day 4.

The most striking finding in this study, however, was the dramatic upregulation of specific microenvironment molecules. MTS 9 normally stains all medullary and infrequent isolated cortical epithelial cells, but following irradiation, MTS 9 was extensively expressed on epithelial cells throughout the thymus, including the collapsed cortex (Fig. 7). With progressive T-cell development, MTS 9 expression retracted such that by day 8 , it was virtually restricted to the medulla. Similarly, MTS 10, a marker of subcapsular and medullary epithelium in the normal adult thymus, displayed some cortical epithelial reactivity PIrr (Figs. 6E-6H). Anti-MHC II normally stains the fine epithelial network in the cortex and dense, almost confluent staining in the medulla involving both epithelial and nonepithelial cells. Following irradiation, MHC II was confluently expressed throughout the thymus. These markers all displayed a normal pattern of thymic reactivity by day 6 PIrr.

Vascular and Connective-Tissue Stromal Elements. MTS 12 (vascular endothelium) was not markedly altered with respect to thymic distribution, but was more obvious presumably because of the loss of lymphocytes (Figs. 8A and 8B). Similarly, MTS 16
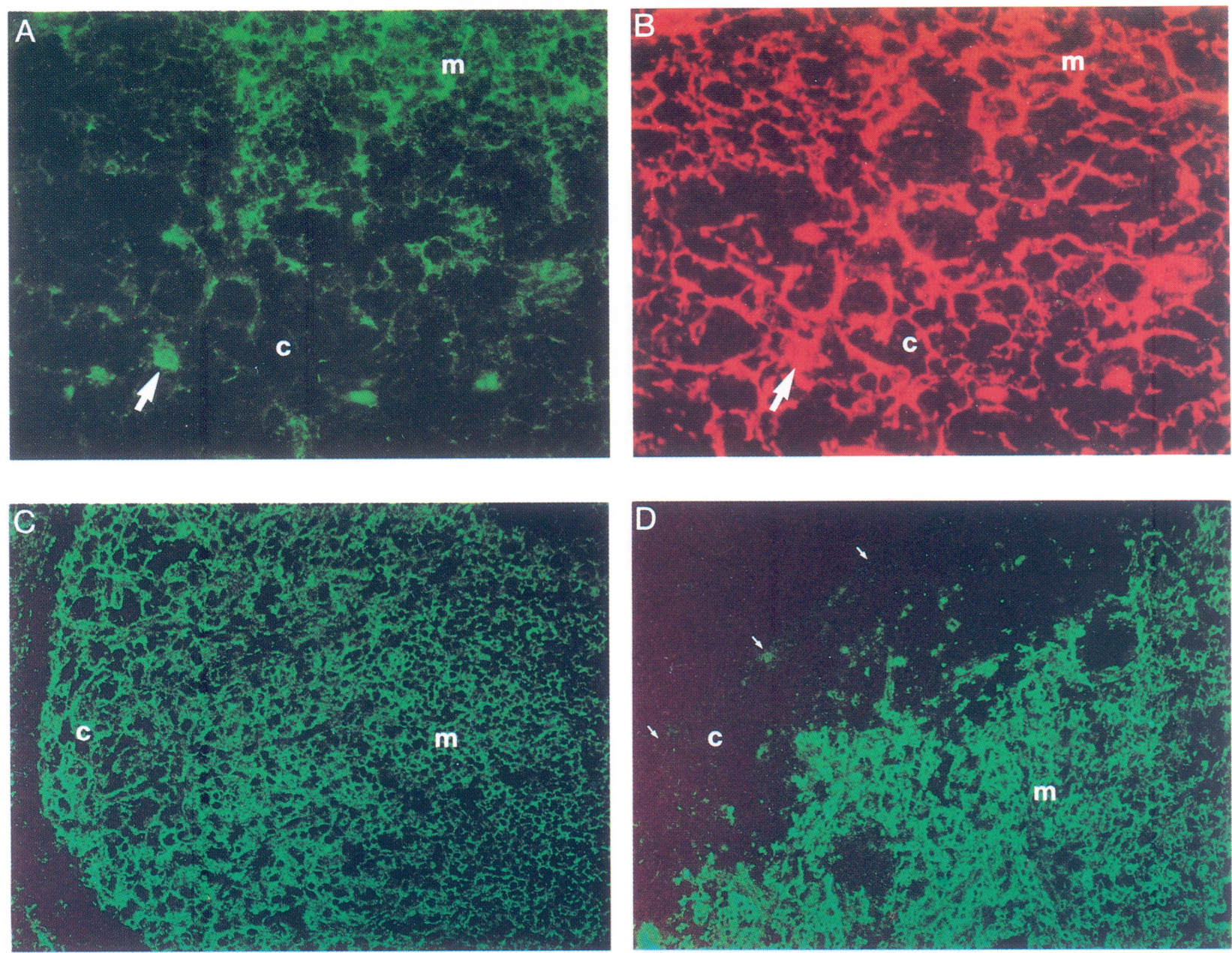

FIGURE 7. Effect of irradiation on epithelial cell subsets. In the normal adult thymus, MTS 9 (green) stains medullary (m) epithelium, isolated cortical (c) epithelial cells (arrow), and thymocyte subsets in the adult thymus (A; $\times 270)$; double-labeled with anti-keratin (red) (B). Post-irradiation, MTS 9 was extensively expressed throughout the thymus (C; 24 h PIrr; $\times 135$ ). By day 6 PIrr; MTS 9 staining was almost completely restricted to the medulla $(\mathrm{D} ; \times 135)$. See Colour Plate III. 

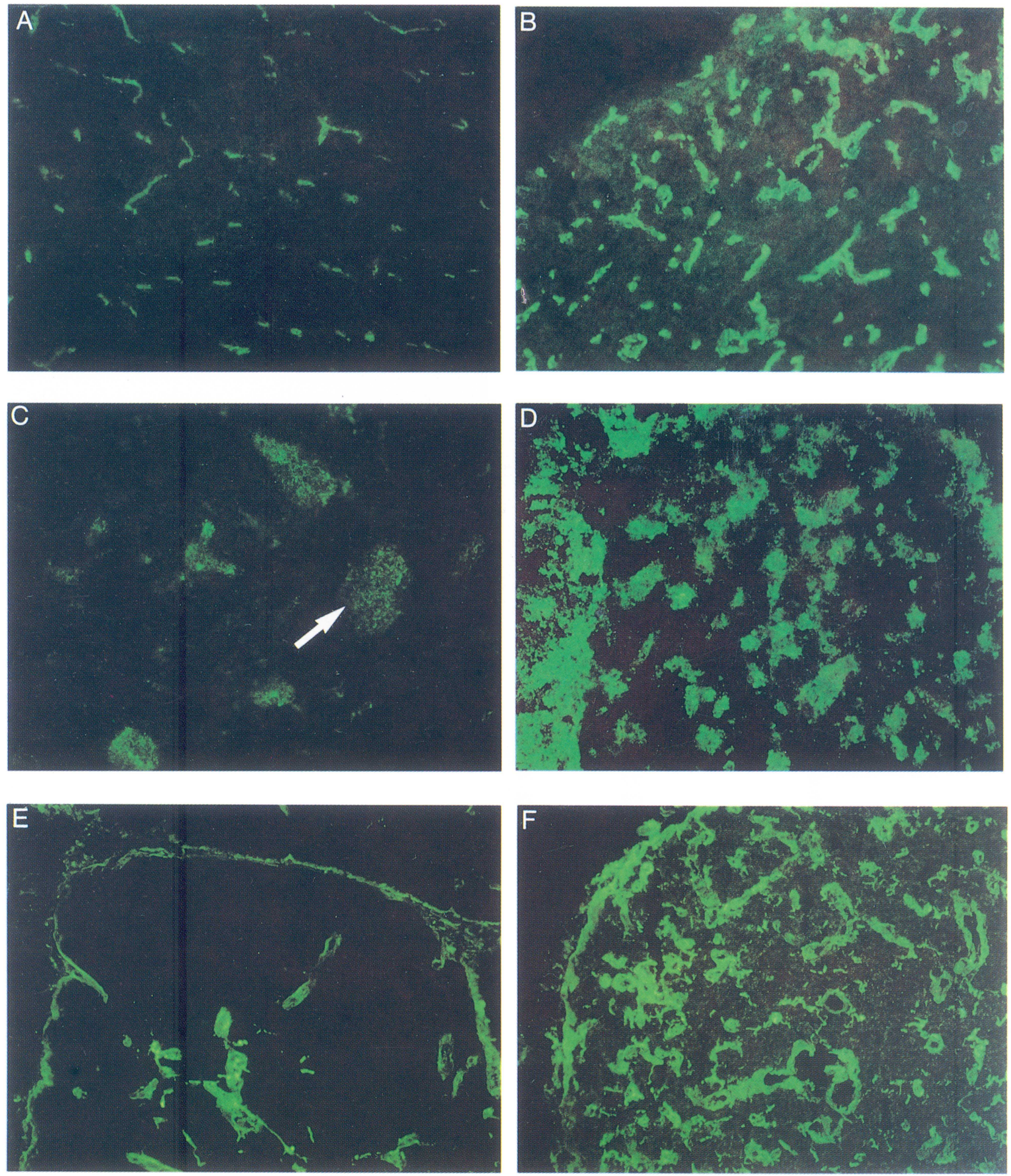

FIGURE 8. Effect of irradiation on the blood-thymus barrier. MTS 12, a marker of capillaries in the normal adult thymus $(\mathrm{A} ; \times 110)$ was enriched in frequency post-irradiation (B; $48 \mathrm{~h}$ PIrr; $\times 110$ ). MTS 16 defined the connective tissue associated with the basement membrane lining the capsule, PVS and BV in the normal adult thymus $(C ; \times 110)$. Post-irradiation MTS 16 reactivity was increased in frequency $(D ;$ $48 \mathrm{~h}$ PIr; $\times 110$ ). MTS 14 detects the connective tissue of the Sc space (arrow), BV and trabeculae in the normal adult thymus (E; $\times 110)$. Post-irradiation MTS 14 reactivity was enhanced and appeared more diffuse (F; 48 h PIrr; $\times 110)$. See Colour Plate IV. 

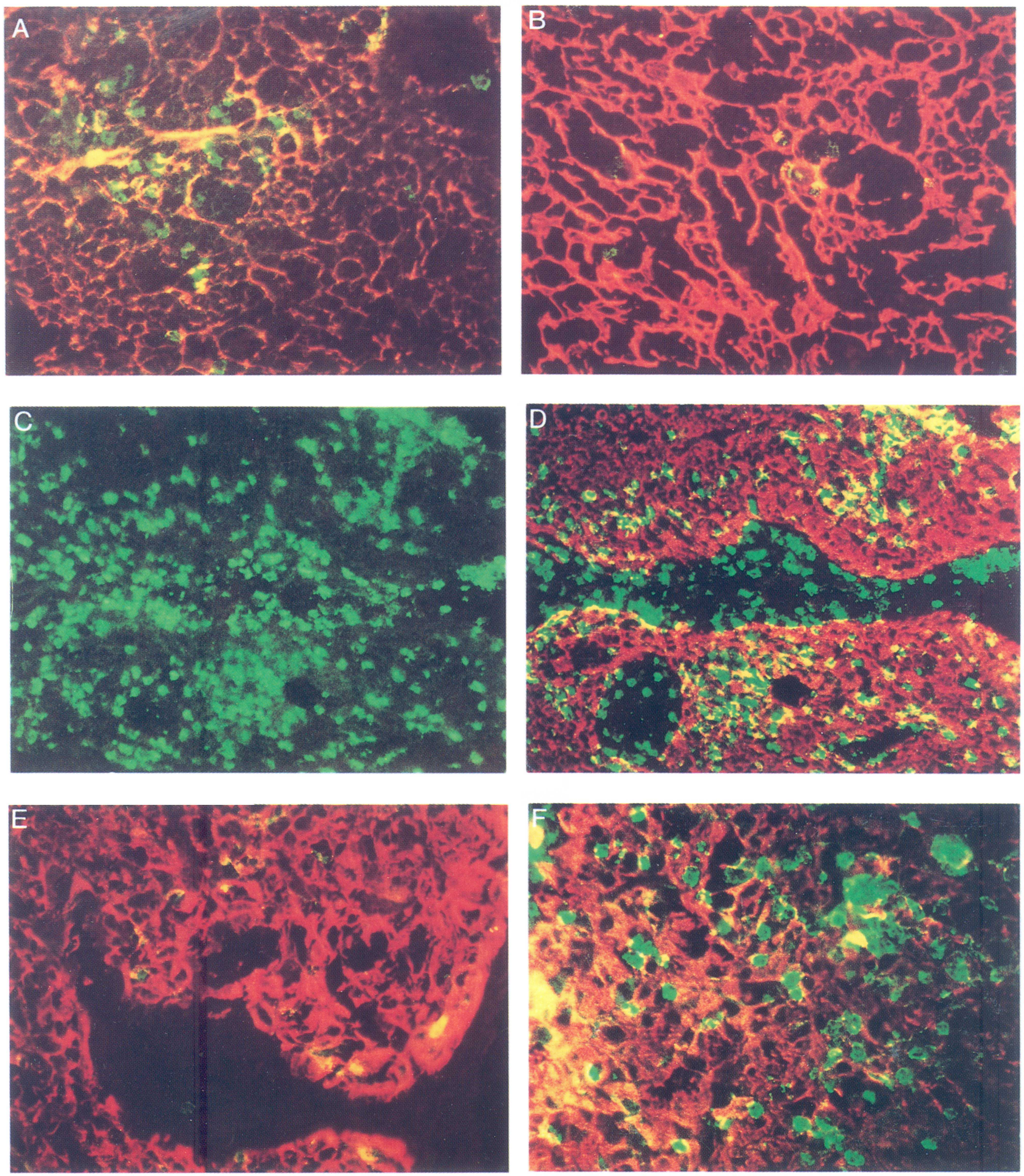

FIGURE 9. Effect of irradiation on nonepithelial cells. In the normal adult thymus, MTS 17 (green) detected M $\phi$-like cells (negative by anti-keratin double-labeling (red) $(\mathrm{A}$ and $\mathrm{B} ; \times 220)$. These were vastly increased in frequency from $24-48 \mathrm{~h}$ PIrr (C; $24 \mathrm{~h}$ PIrr; $\times 110$ ). (D) Double-label exposure showing MTS $17^{+}$cells (green) interspersed throughout the epithelium (anti-keratin, red), and in the connective tissue space between two lobules $(\times 220)$. MTS 17 staining was significantly reduced in frequency by $48 \mathrm{~h}$ PIrr $(\mathrm{E}$; $\times 220$ ), although was still greater than that in the normal adult thymus. Mac- 1 followed a similar distribution to $\mathrm{MTS}^{17^{+}}$cells, although they were more frequent at $48 \mathrm{~h}$ PIrr $(\mathrm{F} ; \times 220)$. See Colour Plate V. 

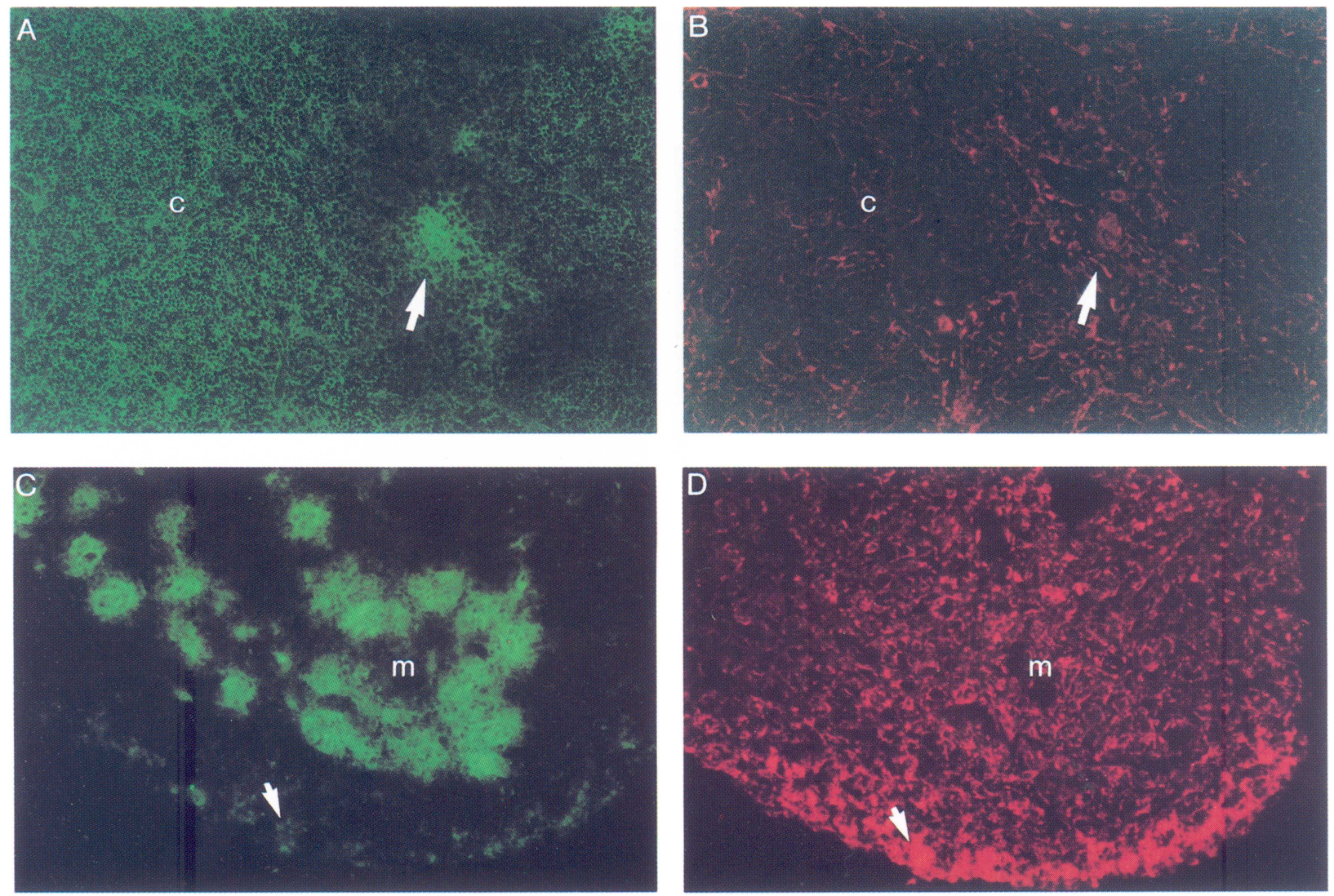

FIGURE 10. Effect of irradiation on antigens shared between thymocytes and epithelial cells. In the nonirradiated adult thymus, MTS 33 (ThB) (green) stains cortical (c) thymocyies and isolated medullary epithelial clusters (arrow) (A; $\times 150)$; anti-keratin (red) (B). After sublethal post-irradiation, MTS 33 displayed no thymocyte reactivity, revealing MTS $33^{+}$-isolated clusters of cortical epithelial cells (arrow) and a more extensive, intense staining of medullary $(\mathrm{m})$ epithelial clusters $(C$; anti-keratin, D; day 4 PIrr; $\times 150)$. See Colour Plate VI.

(extracellular matrix surrounding the vasculature) was still localized to these regions, but had increased in expression (Figs. 8E and 8F). Both antigens remained prominent through to day 6 PIrr, and by day 12 , showed the normal distribution. MTS 15 normally stains a vascular endothelium-derived antigen, the granular pattern of which suggests it is secreted. It labels the area immediately surrounding some blood vessels, including their perivascular spaces and some regions in the subcapsular spaces. PIrr, the MTS 15 staining was more much extensive with all perivascular regions being positive (Figs. 8C and $8 \mathrm{D})$. By day 12 PIrr, MTS 15 had attained a normal thymic distribution.

Isolated Stromal Elements. In the adult thymus, MTS 17 detects distinct populations of isolated, keratinnegative $\mathrm{M} \phi$-like cells that are predominantly in the subcapsular and subtrabecular connective tis- sue and medulla and less frequently throughout the cortex. These MTS $17^{+}$cells were vastly increased in frequency throughout the thymus following irradiation (Figs. 9A to 9D), particularly within the first $24 \mathrm{~h}$. These cells closely followed the distribution of MAC-1 (Figs. 9E and 9F), although the staining appeared more diffuse. This was most likely due to the cytoplasmic reactivity of MTS 17, as opposed to the plasma membrane staining of MAC-1. As of day 2 PIrr, the majority of MTS $17^{+}$cells were now localized to the medulla, including being associated with Hassall's corpuscles. By day 6, the levels and distribution of MTS 17 and MAC-1 expression had returned to normal.

MTS 29, normally a marker of isolated medullary epithelial cells, was not dramatically effected by the sublethal irradiation, although MTS $29^{+}$nonepithelial cells became evident. 
Thymocyte-Stromal Shared Antigens. By immunohistology, MTS 32 normally detects a marker expressed on cortical thymocytes and isolated epithelial cells; the medulla by contrast is negative. By days 1-2 PIrr, the expressions of MTS 32 had vanished, leaving weak isolated epithelial cell staining in the cortex. Pockets of granular staining (possibly dead/ dying thymocytes) were also observed within epithelial cell-free regions. From days 3-6, MTS 32 remained weakly localized to infrequent epithelial cells and thymocytes within the cortex; reactivity had normalized by day 12 . MTS 33 (ThB), normally reactive with cortical thymocytes and medullary epithelial clusters, displayed no thymocyte reactivity, but the latter were more obvious from days 1-6 PIrr, presumably as a result of the absence of T cells. Additionally, isolated clusters of weak $\mathrm{ThB}^{+}$epithelial cells were revealed in the subcapsular cortex (Fig. 10).

In accordance with flow cytometry, MTS 35 (TSA1/Sca-2) and MTS 37 (HSA) were all negative on thymocytes from days $1-5$, their reactivity on both cortical and medullary thymic stromal-cell subsets being more exposed. By day 6 , their staining patterns had normalized.

\section{DISCUSSION}

In view of the recent realization that a major feature of thymic organogenisis is the bidirectional, symbiotic development relationship between thymic lymphocytes and stromal cells, the purpose of this study was to examine the responsiveness of these stromal cells to a dramatic loss in $\mathrm{T}$ cells. That is, has the microenvironment encompassed within the stromal elements the flexibility to alter in response to the need to reinitiate or enhance $\mathrm{T}$-cell differentiation? If so, can such a study reveal which specific stromal molecules are involved in this important process?

In addition to the anticipated dramatic loss of thymocytes, the most striking feature of the present study was the enhanced staining of selective thymic stromal-cell antigens following sublethal irradiation. There are three plausible explanations for this. Antigenic determinants, normally camouflaged by thymocytes, may have simply been exposed due to the loss of lymphocytes; the stromal cells may be responding directly to the effects of the irradiation; the sudden loss of thymocytes may have caused an upregulation in the stromal cell expression of these antigens. In accordance with clearly established data of previous studies (Takada et al., 1969; Huiskamp et al., 1983; Huiskamp and van Ewijk, 1985; Huiskamp et al., 1985), following irradiation there was indeed a dramatic decrease in thymic mass and collapse of the cortical stromal network through the loss of immature thymocytes. The developmental status of the remnant and regenerating $\mathrm{T}$ cells was verified not only by the changes in CD3, CD4, and CD8 profiles and the collapsed cortex, but also by the loss of TSA-1/Sca-2 (MTS 35), ThB (MTS 33), and HSA (MTS 37 ) positive cells. MTS 35 detects the antigen TSA-1/Sca-2, which is expressed only on immature thymocytes and is normally absent on peripheral T cells (Godfrey et al., 1992). Similar to HSA, ThB is present on most thymocytes, including the mature $\left(\mathrm{CD}^{+}\right) \mathrm{CD} 4$ and $\mathrm{CD} 8$ single-positive populations, but is absent on peripheral $\mathrm{T}$ cells (Tucek et al., 1992). By days 3-4 PIrr, there was virtually no staining for ThB and HSA. This was surprising as phenotypically mature thymocytes were still present. It is possible that these antigens are radiosensitive or are cleaved by macrophagereleased proteases, but this would infer that the stromal cells that are still stained by the mAbs express different, more stable conformations of the antigens. There is no evidence to suggest immigration of mature peripheral ( $\mathrm{HSA}^{-}$and $\mathrm{ThB}^{-}$negative) $\mathrm{T}$ cells into the irradiated thymus. The apparent buildup of $\mathrm{CD}^{+}{ }^{+} \mathrm{CD} 4^{-} \mathrm{CD} 8^{-}$and $\mathrm{CD} 3^{+} \mathrm{CD} 4^{-} \mathrm{CD} 8^{+}$ thymocytes presumably indicates a lag between phenotypic and functional (at least in terms of migration ability) maturity or it reveals a population of cells that may never leave the thymus reflecting the very low migration rate $(\sim 1 \% /$ day; Scollay et al., 1980).

Given the dramatic loss of cortical thymocytes, this could in principle expose the stromal antigens and hence the appearance of increased expression. This in part may be an explanation, but it does not account for the selective nature of the upregulated antigens and in any case would only be relevant in the cortex, but several antigens were enhanced in the medulla (MTS 9, 14, 16, 17, and 29). From a purely technical viewpoint, it is also unlikely that the lymphocytes would normally sterically mask stromal antigens because they are nonoverlapping independent cell types and examined in the same plane of the section. Direct irradiation induced enhancement of the stromal antigens is also unlikely because we have observed similar, albeit less pronounced, increases following thymocyte depletion with hydrocortisone and 5-fluorouracil (unpub- 
lished observations). We thus favor the hypothesis that although some of the increases may be part of the "housekeeping" repair mechanisms following architectural damage to the thymus, they are essentially a direct response of the stromal-cell subsets to specifically reestablish a microenvironment geared to reinitiating or elevating basal levels of T-cell differentiation. Indeed, such specific upregulation of these molecules may be a generic feature of the thymus undergoing elevated thymopoiesis because we have found similar selective upregulation of stromal antigens during early ontogenesis (E14) and in the postcastration reversal of thymic atrophy (Price et al., manuscript in preparation).

Within the first 2 days following irradiation, TN thymocytes did not alter significantly, indicating their relative resistance to the irradiation; as to whether there were subtle shifts in the CD44/ CD25/c-kit defined TN subsets was not determined. It is from within these TN cells that reconstitution begins around day 4 is rapidly expanded by day 7 and is virtually complete by day 21 . High levels of $\left[{ }^{3} \mathrm{H}\right] \mathrm{TdR}$ incorporation (Kadish and Basch, 1975; Sharp and Thomas, 1975) and increased lymphocyte reactivity of the mAb MTS $35,32,37$, and ThB also indicated this to be a time of active cell division and increased immature thymocyte content.

Based on the findings reported herein, a synopsis of the intrathymic events following sublethal irradiation would be as follows. The initial and probably sole direct effect of the irradiation is the immediate loss of immature thymocytes, excluding the nondividing TN precursors. This causes an associated collapse of the cortex, the epithelium of which is still present, but as a compact zone of MTS $44^{+}$cells surrounding the medulla. From 24 to $72 \mathrm{~h}$, there was a dramatic increase in macrophages and/ or myeloid cells revealed by enhanced MAC-1, MTS 17, MTS 37, and MTS 28 (data not shown) staining, presumably in response to the need to remove the dead and dying thymocytes. This increase in phagocytic cells is in agreement with earlier reports (Duijvestijn et al., 1982; Huiskamp et al., 1985). The loss of thymocytes was also associated with a marked increase in expression of antigens associated with the vasculature. Because it is unlikely that significant angiogenesis occurred during this time, the apparent increase in vascular endothelium (MTS $12^{+}$) was more likely due to it being exposed. There was, however, an upregulation in the expression of the secreted endothelial antigen detected by MTS 15 and the extracellular matrix associated with the vasculature (MTS 16). Although the latter may be part of a tissue rebuilding process, we have also observed such endothelial activation in the regenerating male mouse thymus following castration (Price et al., manuscript in preparation). Hence as TN thymic precursors are localized around the thymic endothelium, it is possible that the vasculature initiates their proliferation and/or differentiation, evident from day 4 PIrr. The dynamic nature of the thymic stromal cells was further demonstrated by the dramatic increase in MTS 9 expression, which virtually stained the entire thymus from $24-72 \mathrm{~h}$ and gradually retracted with the increase in newly generated $\mathrm{T}$ cells, to the predominantly medullary epithelium pattern by day 6 .

Hence, despite the widely held view that thymic stromal cells are a sessile population, they are capable of rapid alteration at both the cellular and molecular levels in response to the sudden depletion of thymocytes or need for renewed thymopoiesis. The post-irradiation model provides a valuable means of revealing this and we are currently using it to test the functional significance of the antigens by injecting the appropriate purified mAbs.

\section{MATERIALS AND METHODS}

\section{Animals}

CBA/CaH male mice 4-6 weeks of age were obtained from the Monash University Central Animal House. The mice were exposed to $7.5 \mathrm{~Gy}$ of whole body $\gamma$ irradiation at a dose rate of $0.3 \mathrm{~Gy} / \mathrm{min}$, at the Walter and Eliza Hall Institute using Eldorado 6 teletherapy unit (Atomic Energy of Canada, Commercial Products) charged with $5000 \mathrm{Ci}$ of ${ }^{60} \mathrm{Co}$. Mice were subsequently killed at $12 \mathrm{~h}$, days 1-14, 21 , and 28 after the irradiation. Results are based on a minimum of four independent experiments and a pool of one to six mice per experiment, depending on the time point.

\section{Cell-Surface Staining}

All labeling for CD3, CD4, and CD8 was performed using anti-CD3-FITC (145-2C11), anti-CD4 phycoerythrin (PE) (GK1.5), and anti-CD8-Biotin (B) (536.7) (CD4 and CD8 both from Becton Dickinson, CA). For three-color labeling, streptavidinphycoerythrin Texas red conjugate (Tandem $^{\mathrm{TM}}$, Southern Biotech, AL) was used to detect the 
biotinylated $\mathrm{mAb}$. To control for labeling efficiency, freshly prepared thymocyte suspensions from normal adult mice were routinely used. For MTS mAb thymocyte reactivity, cells were indirectly labeled with the desired $\mathrm{mAb}$ followed by FITC-conjugated sheep anti-rat Ig (Silenus Laboratories). Stained cells were monitored using a FACScan (Becton Dickinson). Dead cells and nonlymphoid cells were excluded from data acquisition on the basis of 0 and $90^{\circ}$ scatter profiles. Analyses were performed using Lysys II research software (Becton Dickinson).

\section{Immunohistology}

Thymii were snap frozen on liquid nitrogen and 4 $\mu \mathrm{m}$ sections were cut using a cryostat. MTS mAb (Godfrey et al., 1990) labeling and the coexpression of epithelial cell determinants were assessed by double-labeling sections with the desired $\mathrm{mAb}$ and a polyvalent rabbit anti-cytokeratin $\mathrm{Ab}$ (Dako, Carpinteria, CA), respectively. Bound $\mathrm{mAb}$ was revealed by FITC-conjugated sheep anti-rat Ig (Silenus Laboratories) and TRITC-conjugated goat antirabbit Ig (Silenus Laboratories). By using these species combinations, no intermediate blocking steps were necessary. For three-color immunofluorescence, sections were labeled with anti-CD4-FITC, anti-CD8-Biotin (both from Becton Dickinson, and the polyvalent rabbit anti-cytokeratin $\mathrm{Ab}$, washed and stained with a mixture of streptavidinphycoerythrin Texas red conjugate Tandem $^{\mathrm{TM}}$, Southern Biotech) and AMCA anti-rabbit Ig (Jackson Immunodiagnostics, WG). Stained sections were washed and mounted under a coverslip using veronal buffered glycerol $(\mathrm{pH}$ 8.6) and examined using a Zeiss Axioskop fluorescence microscope. All photography was performed using Kodak 1000 ASA print or 1600 slide films.

\section{ACKNOWLEDGMENTS}

The authors would like to thank Miss Anna Romeo and Dr. Leon Martin for advice regarding FCM, Dr. Dale Godfrey for his valuable discussion and photographic contributions, and Dr. Carolyn Tucek-Szabo for her early participation in this project. This work was supported by grants from the Australian National Health and Medical Research Council and the Anti-Cancer Council of Victoria.

(Received April 5, 1994)

(Accepted September 2, 1994)

\section{REFERENCES}

Adkins B., Gandour D., Strober S., and Weissman I. (1988). Total lymphoid irradiation leads to transient depletion of the mouse thymic medulla and persistent abnormalities among medullary stromal cells. J. Immunol. 140: 3373-3379.

Anderson G., Jenkinson E.J., Moore N.C., and Owen J.J.T. (1993). MHC class II-positive epithelium and mesenchyme cells are both required for $\mathrm{T}$-cell development in the thymus. Nature 362: 70-73.

Andrews P., and Boyd R.L. (1985). The murine thymic nurse cell: An isolated thymic microenvironment. Eur. J. Immunol. 15: 36-42.

Boyd R.L., and Hugo P. (1991). Towards an intergrated view of thymopoiesis. Immunol. Today 12: 71-79.

Boyd R.L., Tucek, CL., Godfrey D.I., Izon D.J., Wilson T.J., Davidson N.J., Bean A.G.D., Ladyman H.M., Ritter M.A., and Hugo P. (1993). The thymic microenvironment. Immunol. Today 14: 445-459.

Couture C., Amarante-Mendes G., and Potworowski E.F. (1992). Tyrosine kinase activation in thymic epithelial cells: Necessity of thymocyte contact through the gp23/45/90 adhesion complex. Eur. J. Immunol. 22: 2579-2585.

Duijvestijn A.M., Kohler Y.G., and Hoefsmit E.C.M. (1982) Inderdigitating cells and macrophages in the acute involuting rat thymus. An electronmicroscopic study on phagocytic activity and population development. Cell. Tissue Res. 224: 291-301.

Gao X., Nishimura T., Takeichi Y., Sudo T., and Habu S. (1993) Thymic nurse cell clone supports the differentiation of $\mathrm{CD} 4^{-} \mathrm{CD} 8^{-}$thymocytes into $\mathrm{CD} 4^{+} \mathrm{CD} 8^{+}$thymocytes in vitro. Immunol. Lett. 35: 169-176.

Godfrey D.I., Izon D.J., Tucek C.L., Wilson T.J., and Boyd R.L. (1990). The phenotypic heterogeneity of mouse thymic stromal cells. Immunol. 70: 66-74.

Godfrey D.I., Masciantonio M., Tucek C.L., Malin M.A., and Boyd R.L. (1992). A novel thymocyte marker discriminating immature from mature thymocyte subsets. J. Immunol. 148: 20062011.

Hiesch K.D., and Revesz L. (1979). Effect of cortisone and $x$-irradiation on cellular depletion and regeneration in the thymus of mice: Experimental discrimination between thymus lymphocyte precursors in the bone marrow and in the thymus. Path. Res. Pract. 164: 157-166.

Hugo P., Kappler J.W., Godfrey D.I., and Marrack P.C. (1992). A cell line that can induce thymocyte positive selection. Nature 360: $679-682$.

Huiskamp R., Davids J.A.G., and Vos O. (1983). Short- and long-term effects of whole body irradiation with fission neutrons or X-rays on the thymus in CBA mice. Rad. Res. 95: 370-381.

Huiskamp R., and van Ewijk W. (1985). Repopulation of the mouse thymus after sublethal fission neutron irradiation. I. Sequential appearance of thymocyte subpopulations. J. Immunol. 134: 2161-2169.

Huiskamp R., van Vliet E., and van Ewijk W. (1985) Repopulation of the mouse thymus after sublethal fission neutron irradiation. II. Sequential changes in the thymic microenvironment. J. Immunol. 134: 2170-2178.

Kadish J.L., and Basch R.S. (1975). Thymic regeneration after lethal irradiation: Evidence for an intra-thymic radioresistant $T$ cell precursor. J. Immunol. 114: 452-458.

Kanariou M., Huby R., Ladyman H., Colic M., Sivolapenko G., Lampert I., and Ritter M. (1989). Immunosuppression with cyclosporin A alters the thymic microenvironment. Clin. Exp. Immunol. 78: 262-270.

Kyewski B.A. (1986). Thymic nurse cells: Possible sites of T cell selection. Immunol. Today 7: 374-379.

Kyewski B.A. (1991). Differential effects of anti-CD3 antibodies 
in vivo and in vitro on $\alpha \beta$ and $\gamma \delta \mathrm{T}$ cell differentiation. Curr. Top. Microbiol. Immunol. 173: 65-69.

Molina T.J., Kishihara K., Siderovski D.P., van Ewijk W., Narendrsn A., Timms E., Wakeham A., Paige C.J., Hartmann K.U., Veillette A., Davidson D., and Mak T.W. (1992). Profound block in thymocyte development in mice lacking p56LcK. Nature 357: 161-164.

Nagamine J., Takeda K., Tatsumi Y., Ogata M., Miyake K., Hamaoka T., and Fujiwara H. (1991). Role of a thymic stromal cell clone in inducing the stage-specific differentiation of various subpopulations of double negative thymocytes. J. Immunol. 147: 1147-1152.

Nishimura T., Takeuchi Y., Ichimura Y., Gao X., Akatsuka A., Tamaoki N., Yagita H., Okumura K., and Habu S. (1990). Thymic stromal cell clone with nursing activity supports the growth and differentiation of murine $\mathrm{CD} 4^{+} 8^{+}$thymocytes in vitro. J. Immunol. 145: 4012-4017.

Palacios R., Studer S., Samaeidis J., and Pelkonen J. (1989). Thymic epithelial cells induce in vitro differentiation of PRO-T lymphocyte clones into $\mathrm{tCR} \alpha, \beta / \mathrm{T} 3+$ and $\mathrm{TCR} \gamma, \delta / \mathrm{T} 3+$ cells. EMBO J. 8: 4053-4063.

Palmer D.B., Viney J.L., Ritter M.A., Hatdat A.C., and Owen M.J. (1993). Expression of the $\alpha \beta$ T-cell receptor is necessary for the generation of the thymic medulla. Dev. Immunol. 3: 175-179.

Philpott K.L., Viney J.L., Kay G., Rastan S., Gardiner E.M., Chae S., Hayday A.C., and Owen M.J. (1992). Lymphoid development in mice congenitally lacking T cell receptor $\alpha \beta$-expressing cells. Science 256: 1448-1452.

Ritter M.A., and Boyd R.L. (1993). Development in the thymus: It takes two to tango. Immunol. Today 14: 462-468.

Scollay R., Butcher E.C., and Weissman I.L. (1980). Thymus cell migration. Quantative aspects of cellular traffic from the thymus to the periphery in mice. Eur. J. Immunol. 10: 210-218.

Sharp J.G., and Thomas D.B. (1975). Thymic regeneration in lethally X-irradiated mice. Radiat. Res. 64: 293-305.

Sharp J.G., and Thomas D.B. (1977). Origin of the radioresistant precursor cells responsible for the initial phase of thymic regeneration after X-irradiation. J. Retic. Soc. 22: 169-179.

Shores E.W., Van Ewijk W., and Singer A. (1991). Disorganization and restoration of thymic medullary epithelial cells in $\mathrm{T}$ cell receptor-negative scid mice: Evidence that receptor-bearing lymphocytes influence maturation of the thymic microenvironment. Eur. J. Immunol. 21: 1657-1661.

Shortman K., and Vremec D. (1991). Different subpopulations of developing thymocytes are associated with adherent (Macrophages) or nonadherent (Dendritic) thymic rosettes. Dev. Immunol. 1: 225-235.

Surh C.D., Ernst B., and Sprent J. (1992). Growth of epithelial cells in the thymic medulla is under the control of mature $T$ cells. J. Exp. Med. 176: 611-616.

Takada A., Takada Y., Huang C.C., and Ambrus J.L. (1969). Biphasic pattern of thymus regeneration after whole body irradiation. J. Exp. Med. 129: 445-456.

Tatsumi Y., Kumanogoh A., Saito M., Mizushima Y., Kimura K., Suzuki S., Yagi H., Horiuchi A., Ogata M., Hamaoka T., and Fujiwara H. (1990). Differentiation of thymocytes from $\mathrm{CD}^{-} 4^{-} 8^{-}$through $\mathrm{CD}^{-} 4^{-} 8^{+}$into more mature stages induced by a thymic stromal cell clone. Proc. Natl. Acad. Sci. USA 87: 2750-2754.

Tucek C.L., Godfrey D.I., and Boyd R.L: (1992). Five novel antigens illustrate shared antigenicity between mouse thymic stromal cells, thymocytes and peripheral lymphocytes. Int. Immunol. 4: 1021-1030.

Vacari A., Abehsira-Amar O., Papiernik M., Boyd R.L., and Tucek C.L. (1994). MTS 32-monoclonal antibody defines $\mathrm{CD}^{+} 8^{-}$ thymocyte subsets that differ in their maturation level, lymphokine secretion, and selection patterns. J. Immunol. 152: 333-335.

Van Ewijk W. (1988). Cell surface topography of thymic microenvironments. Lab Invest. 59: 579-590.

Van Ewijk W., Shores E.W., and Singer A. (1994). Crosstalk in the mouse thymus. Immunol. Today 15: 214-217.

Watanabe Y., Mazda O., Aiba Y.K.I., Gyotoku J., Ideyama S., Miyazaki J., and Katsura Y. (1992). A murine thymic stromal cell line which may support the differentiation of $\mathrm{CD}^{-} 8^{-}$ thymocytes into $\mathrm{CD} 4^{+} 8^{-} \alpha \beta \mathrm{T}$ cell receptor positive $\mathrm{T}$ cells. Cell Immunol. 142: 385-397. 


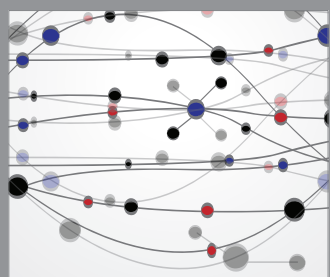

The Scientific World Journal
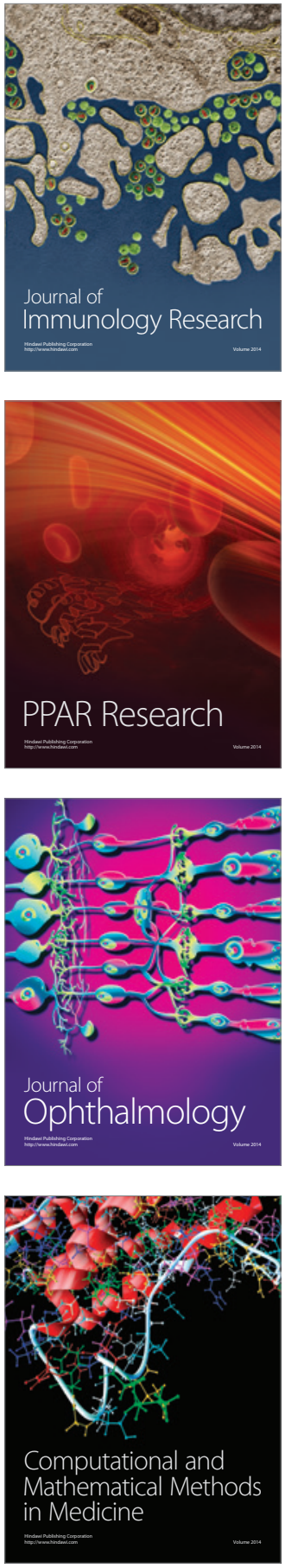

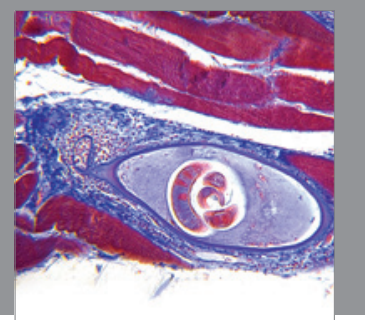

Gastroenterology

Research and Practice
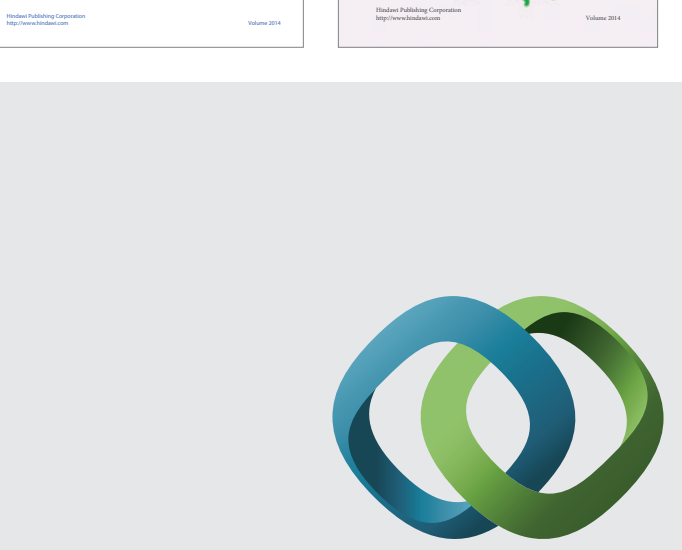

\section{Hindawi}

Submit your manuscripts at

http://www.hindawi.com
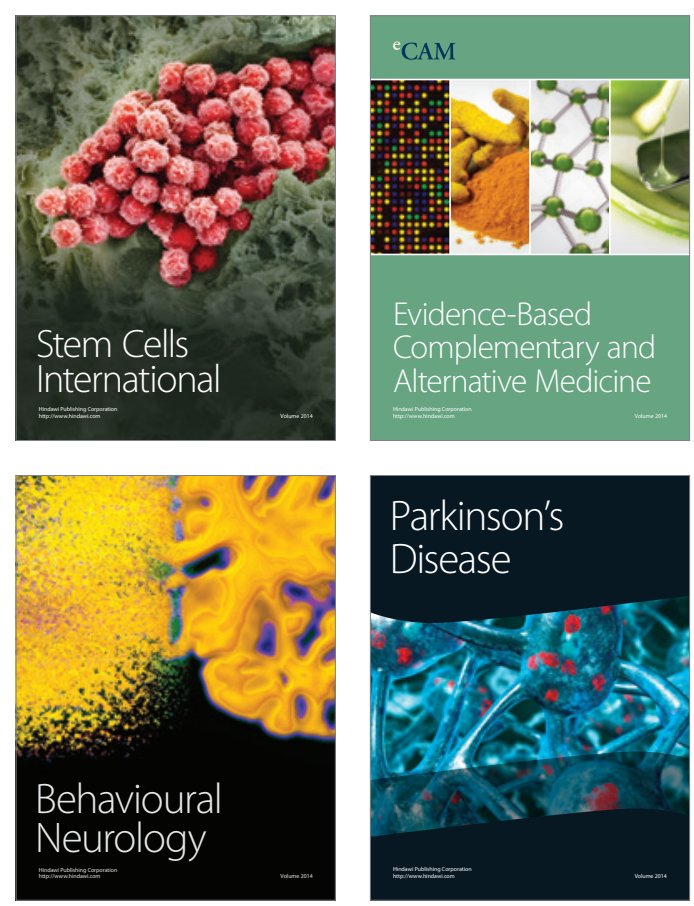

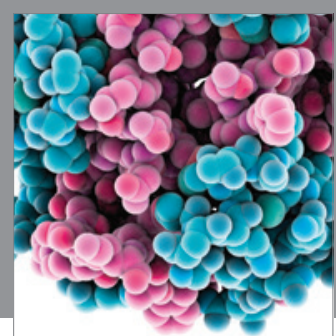

Journal of
Diabetes Research

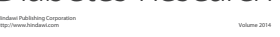

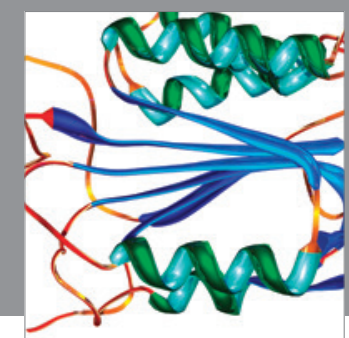

Disease Markers
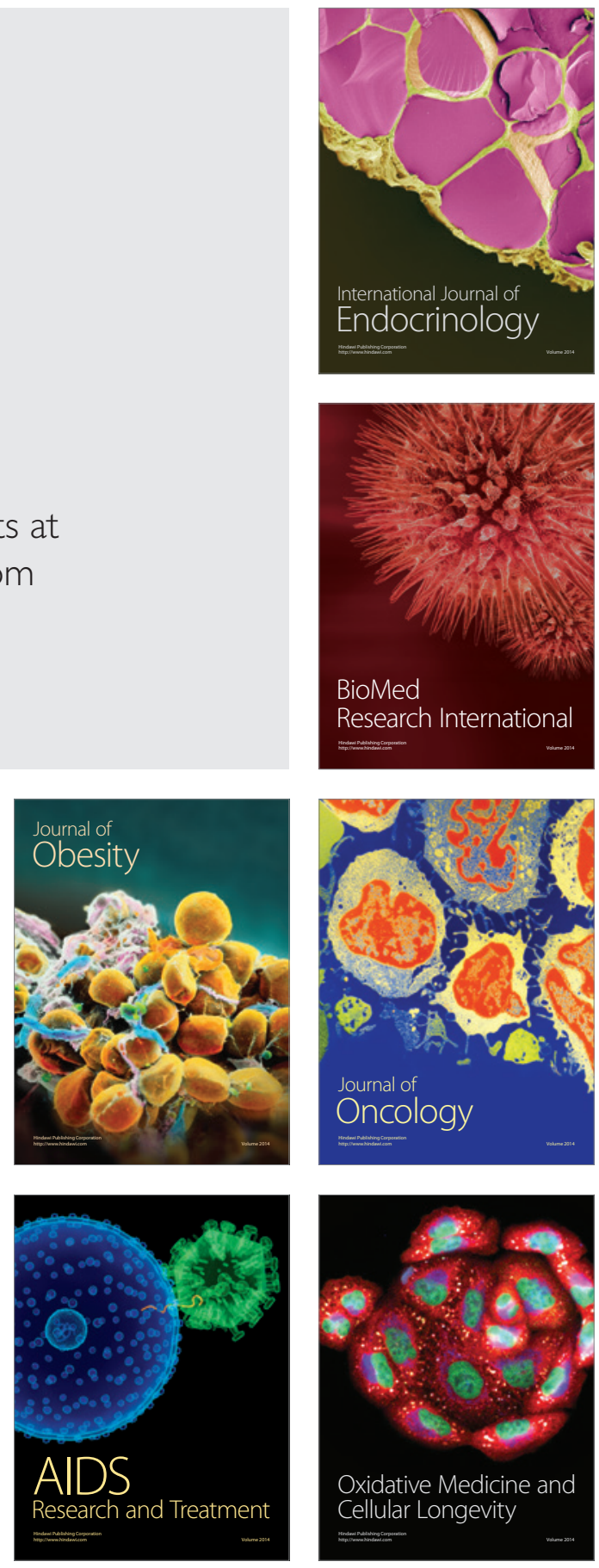